\title{
What is new in the 2017 ESC clinical practice guidelines
}

\author{
Management of acute myocardial infarction in patients presenting with \\ ST-segment elevation
}

\author{
Irene M. Lang $\mathbb{D}$
}

Received: 21 October 2017 / Accepted: 13 November 2017 / Published online: 23 May 2018

(C) The Author(s) 2018

\begin{abstract}
Summary Guidelines and recommendations are designed to guide physicians in making decisions in daily practice. Guidelines provide a condensed summary of all available evidence at the time of the writing process. Recommendations take into account the risk-benefit ratio of particular diagnostic or therapeutic means and the impact on outcome, but not monetary or political considerations. Guidelines are not substitutes but are complementary to textbooks and cover the European Society of Cardiology (ESC) core curriculum topics. The level of evidence and the strength of recommendations of particular treatment options were recently newly weighted and graded according to predefined scales. Guidelines endorsement and implementation strategies are based on abridged pocket guidelines versions, electronic version for digital applications, translations into the national languages or extracts with reference to main changes since the last version. The present article represents a condensed summary of new and practically relevant items contained in the 2017 European Society of Cardiology (ESC) guidelines for the management of acute myocardial infarction in patients with STsegment elevation, with reference to key citations.
\end{abstract}

\section{ESC Guidelines for the management of acute myocardial infarction in patients presenting with ST-segment elevation: Classes of recommendations and level of evidence of particular treatment options were newly weighted and graded according to predefined scales, as outlined in Fig. 1 and 2.}

\section{M. Lang, MD ( $\triangle)$}

Department of Internal Medicine II, Division of Cardiology,

Vienna General Hospital, Medical University of Vienna,

Währinger Gürtel 18-20, 1090 Vienna, Austria

irene.lang@meduniwien.ac.at
Keywords Atherosclerosis · Heart disease - Acute coronary syndromes

Radial access is recommended over femoral access if performed by an experienced radial operator $(1, A)$

In a recent randomized, multicenter, superiority trial [2] of 8404 patients with acute coronary syndrome (ACS), radial angiography and percutaneous coronary intervention (PCI) reduced non-coronary artery bypass surgery (CABG)-associated bleeding (RR 0.67) and all-cause mortality (RR 0.72) compared with femoral access. The data reinforce previous observations from the radial versus femoral access for coronary intervention (RIVAL) access for coronary intervention trial [3], and the radial versus femoral randomized investigation in ST elevation acute coronary syndrome (RIFLE-STEACS) trial [4].

Stenting with new generation drug-eluting stents (DES) is recommended over bare metal stents (BMS) for primary $\mathrm{PCl}(1, \mathrm{~A})$

In a multicenter, multinational, prospective, randomized, single-blinded, controlled trial in patients with ST elevation myocardial infarction (STEMI), the everolimus-eluting stents (EES) versus bare-metal stents (BMS) in ST-segment elevation myocardial infarction (EXAMINATION) trial, the combined endpoint of all-cause death, any recurrent myocardial infarction (MI), and any revascularization, target lesion revascularization and stent thrombosis occurred in 108 ( $14.4 \%$ of 751 patients of the EES group) and in 129 (17.3\% of 747 patients of the BMS group, $p=0.11$ ) at 2 years. The rates of target lesion revascularization and stent thrombosis were significantly lower in the EES group than in the BMS group. Thus, safety and 
Fig. 1 Classes of recommendations [1]. Reproduced by permission of Oxford University Press on behalf of the European Society of Cardiology. (C) The European Society of Cardiology 2017. All rights reserved. For permissions please email journals.permissions@oup.com. This figure is not included under the Creative Commons CC BY license of this publication. Please visit: www.escardio.org/ Guidelines/

\begin{tabular}{|c|c|c|}
\hline $\begin{array}{l}\text { Classes of } \\
\text { recommendations }\end{array}$ & Definition & $\begin{array}{l}\text { Sugges ted wording } \\
\text { to use }\end{array}$ \\
\hline Class I & $\begin{array}{l}\text { Evidence and/or general agreement that } \\
\text { a given treatment or procedure is beneficial, } \\
\text { useful, effective. }\end{array}$ & $\begin{array}{l}\text { Is recommended/ } \\
\text { is indicated. }\end{array}$ \\
\hline Class II & $\begin{array}{l}\text { Conflicting evidence and/or a divergence of } \\
\text { opinion about the usefulness/efficacy of the } \\
\text { given treatment or procedure. }\end{array}$ & \\
\hline Class IIa & $\begin{array}{l}\text { Weight of evidence/opinion is in favor of } \\
\text { usefulness/efficacy. }\end{array}$ & $\begin{array}{l}\text { Should be } \\
\text { considered. }\end{array}$ \\
\hline Class IIb & $\begin{array}{l}\text { Usefulness/efficacy is less well established by } \\
\text { evidence/opinion. }\end{array}$ & May be considered. \\
\hline Class III & $\begin{array}{l}\text { Evidence or general agreement that the given } \\
\text { treatment or procedure is not useful/effective, } \\
\text { and in some cases may be harmful. }\end{array}$ & Is not recommended \\
\hline
\end{tabular}

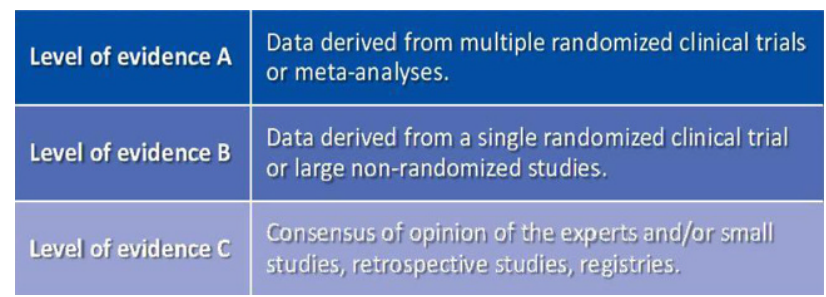

Fig. 2 Level of evidence [1]. Reproduced by permission of Oxford University Press on behalf of the European Society of Cardiology. (C) The European Society of Cardiology 2017. All rights reserved. For permissions please email journals.permissions@oup.com. This figure is not included under the Creative Commons CC BY license of this publication. Please visit: www.escardio.org/Guidelines/

efficacy of EES compared with BMS in the setting of STEMI were confirmed.

In another study [5], 9013 patients undergoing any PCI were randomized to implantation of EES, zotarolimus-eluting stents or BMS. At 6 years, there were no significant between-group differences in the composite of death from any cause and nonfatal spontaneous MI; however, the 6-year rates of any repeat revascularization were $16.5 \%$ in the group receiving DES and $19.8 \%$ in the group receiving BMS (hazard ratio, 0.76; 95\% confidence interval CI, 0.69-0.85; $P<$ $0.001)$ and the rates of definite stent thrombosis were $0.8 \%$ and $1.2 \%$, respectively $(P=0.0498)$.

In the comparison of biolimus eluted from an erodible stent coating with bare metal stents in acute ST elevation myocardial infarction (COMFORTABLE) trial [6] 1161 STEMI patients were randomly assigned to biolimus-eluting stent (BES) or BMS. At 2 years, differences in the primary end point of cardiac death, target vessel MI, and target lesion revascularization continued to diverge in favor of BES-treated patients (5.8\%) compared with BMS-treated patients (11.9\%; $P<0.001$ ), with a significant risk reduction during the second year of follow-up (hazard ratio 1-2 years =
0.45; 95\% CI, $0.20-1.00 ; P=0.049$ ). At 13 months, angiographic in-stent diameter stenosis was less in BES-treated lesions $(12.0 \pm 7.2 \%)$ than in BMS-treated lesions $(39.6 \pm 25.2 \%, P<0.001)$.

Routine revascularization of non-IRA lesions should be considered in STEMI patients with multivessel disease before hospital discharge (Ila, C)

In patients with STEMI and multivessel coronary artery disease undergoing infarct artery PCI, preventive PCI in non-infarct coronary arteries with major stenosis $(n=234)$ significantly reduced the risk of death from cardiac causes $(0.34 ; 95 \%$ CI, 0.11-1.08), nonfatal MI $(0.32 ; 95 \%$ CI, $0.13-0.75)$ or refractory angina $(0.35 ; 95 \%$ CI, 0.18-0.69) compared with no preventive PCI (231 patients), with 9 events per 100 patients and 23 per 100, respectively [7].

In a prospective study [8], 313 patients were 1:1 randomized to no further invasive treatment after primary PCI (PPCI) of the infarct-related artery only and 314 were assigned to fractional flow reserve (FFR) guided complete revascularization. Events comprising the primary endpoint were recorded in $68(22 \%)$ patients who had PCI of the infarct-related artery only and in 40 (13\%) patients who had complete revascularization (hazard ratio $0.56,95 \%$ CI $0.38-0.83$; $p=0.004)$. The data show that complete revascularization guided by FFR measurements significantly reduces the risk of future events.

Similar data resulted from a further study that assigned 885 patients with STEMI and multivessel disease who had undergone PPCI of an infarct-related coronary artery in a 1:2 ratio to undergo complete FFR-guided revascularization of non-infarct-related coronary arteries (295 patients) or to not undergo revascularization of non-infarct-related coronary arteries (590 patients) [9] and 8 versus 21 events occurred per 100 patients, respectively. 
The complete versus lesion-only primary PCI trial (CvLPRIT) was a UK open-label randomized study comparing complete revascularization at index admission with treatment of the infarct-related artery (IRA) only [10] and randomized 296 patients in 7 UK centers. Complete revascularization was performed either at the time of PPCI or before hospital discharge ( $n=150)$. A composite of all-cause death, recurrent MI, heart failure, and ischemia-driven revascularization within 12 months occurred in $10.0 \%$ of the complete revascularization group versus $21.2 \%$ in the IRA only revascularization group $(n=146)$.

In patients with heparin-induced thrombocytopenia, bivalirudin is recommended as the anticoagulant agent during primary $\mathrm{PCI}(\mathrm{I}, \mathrm{C})$; however, the recommendation to routinely use bivalirudin has been weakened (was $1, A$, is now Ila, A)

The MATRIX trial including 8404 patients with acute coronary syndrome, with or without ST-segment elevation, demonstrated that the use of radial access compared with femoral access decreased net adverse clinical events. In a posthoc analysis of 7213 patients who were randomly allocated to bivalirudin or unfractionated heparin, no evidence was found for an interaction between the effect of radial versus femoral access and allocation to bivalirudin or unfractionated heparin for the two co-primary outcomes, all-cause mortality, or Bleeding Academic Research Consortium (BARC) 3 or 5 bleeding ( $p$ for interaction $\geq 0.64$ ), although bivalirudin was used during percutaneous coronary intervention in more than $40 \%$ of patients [2].

In an open-label, randomized controlled trial, 1812 patients undergoing PPCI at Liverpool Heart and Chest Hospital [11] were randomly allocated (1:1) to heparin $(70 \mathrm{U} / \mathrm{kg}$ body weight) or bivalirudin (bolus $0.75 \mathrm{mg} / \mathrm{kg}$; infusion $1.75 \mathrm{mg} / \mathrm{kg}$ per h). The primary efficacy outcome occurred in 79 (8.7\%) of 905 patients in the bivalirudin group and 52 (5.7\%) of 907 patients in the heparin group (absolute risk difference $3.0 \%$; relative risk RR 1.52, 95\% CI 1.09-2.13, $p=0.01$ ). The primary safety outcome occurred in 32 (3.5\%) of 905 patients in the bivalirudin group and 28 (3.1\%) of 907 patients in the heparin group (absolute risk difference $0.4 \%$; relative risk [RR] $1.15,95 \% \mathrm{CI}$ $0.70-1.89, p=0.59)$. The data show that compared with bivalirudin, heparin reduces the incidence of major adverse ischemic events in the setting of PPCI, with no increase in bleeding complications.

\section{Routine use of i.v. enoxaparin should be considered in STE-ACS in the context of primary PCI (lla, A)}

An i. v. bolus of enoxaparin $0.5 \mathrm{mg} / \mathrm{kg}$ was compared with UFH in the randomized open-label Acute MI Treated with primary angioplasty and inTravenous
enOxaparin or unfractionated heparin to Lower ischemic and bleeding events at short and Long-term follow-up (ATOLL) trial, including 910 STEMI patients [12]. The primary composite endpoint of 30-day death, MI, procedural failure, or major bleeding was not significantly reduced by enoxaparin ( $17 \%$ relative risk reduction, $P=0.063)$, but there was a reduction in the composite main secondary endpoint of death, recurrent MI or ACS, or urgent revascularization. Importantly, there was no evidence of increased bleeding with enoxaparin [13].

In a meta-analysis of 23 PCI trials (30,966 patients, $33 \%$ PPCI), enoxaparin was associated with a significant reduction in death compared to UHF. This effect was particularly significant in the context of PPCI and was associated with a reduction in major bleeding [14].

Cangrelor may be considered in the catheter laboratory if P2Y12 inhibitors have not been given (IIB, A)

A prespecified, pooled analysis of patient-level data from three trials (CHAMPION-PCI, CHAMPIONPLATFORM, and CHAMPION-PHOENIX) compared cangrelor with control (clopidogrel or placebo) for prevention of thrombotic complications during and after PCI. Trial participants were patients undergoing PPCI for STEMI (11.6\%), non-ST-elevation ACS $(57.4 \%)$, and PCI for stable coronary artery disease (31.0\%). Efficacy was assessed in the modified intention-to-treat population of 24,910 patients. Cangrelor reduced the odds of death, MI, ischemia-driven revascularization, or stent thrombosis at $48 \mathrm{~h}$ by $19 \%$ ( $p=$ $0.0007)$, and stent thrombosis by $41 \%$ ( $p=0.0008)$; however, cangrelor increased global use of strategies to open occluded coronary arteries (GUSTO) mild bleeding ( $16.8 \%$ vs. $13.0 \%, p<0.0001$ ) [15].

\section{Routine use of thrombus aspiration is not recommended (III, A)}

The TOTAL trial assigned 10,732 patients with STEMI undergoing PPCI to a strategy of routine upfront manual thrombectomy versus PCI alone. Routine manual thrombectomy did not reduce the risk of cardiovascular death, recurrent MI, cardiogenic shock, or NYHA class IV heart failure within 180 days but was associated with an increased rate of stroke within 30 days (hazard ratio, 2.06; 95\% CI, 1.13-3.75; $P=0.02$ ) [16].

The TASTE trial was a multicenter, prospective, randomized, controlled, open-label clinical trial, with enrolment of patients from the national comprehensive Swedish coronary angiography and angioplasty registry (SCAAR). A total of 7244 patients with STEMI undergoing PCI were randomly assigned to manual thrombus aspiration followed by PCI or to PCI only. Routine thrombus aspiration before PCI did not reduce 30-day mortality. There were no significant dif- 
ferences between the groups with respect to the rate of stroke or neurologic complications at the time of discharge $(P=0.87)$ [17].

Early discharge (within 48-72 h) should be considered appropriate in selected low-risk patients if early rehabilitation and adequate follow-up are arranged (Ila, A)

The optimal length of stay in the CCU/ICCU and hospital should be determined on an individual basis. Data are accumulating that after appropriate risk stratification, early discharge is safe [18-22].

\section{Routine oxygen is not recommended in patients with $\mathrm{SaO} 2 \geq 90 \%$ (III, B)}

The DETO2X-AMI trial randomly assigned 6629 patients with suspected MI and an oxygen saturation of $90 \%$ or higher to receive either supplemental oxygen (6 l per min for 6-12 h, delivered through an open face mask) or ambient air. The median duration of oxygen therapy was $11.6 \mathrm{~h}$, and the median oxygen saturation at the end of treatment was $99 \%$ among patients assigned to oxygen and $97 \%$ among patients assigned to ambient air. Hypoxemia developed in 62 patients (1.9\%) in the oxygen group, compared with 254 patients $(7.7 \%)$ in the ambient air group. The primary end point of death from any cause within 1 year after randomization occurred in $5.0 \%$ of patients assigned to oxygen and in $5.1 \%$ of patients assigned to ambient air $(P=0.80)[23]$.

\section{If indicated a $50 \%$ dose of tenecteplase should be considered in patients $\geq 75$ years old (Ila, B)}

The STREAM trial randomly assigned 1892 patients with STEMI who presented within $3 \mathrm{~h}$ after symptom onset and who were unable to undergo PPCI within $1 \mathrm{~h}$ to PPCI or fibrinolytic therapy with bolus tenecteplase, clopidogrel, and enoxaparin. A composite of death, shock, congestive heart failure, or reinfarction up to 30 days occurred in 116 of the 939 patients $(12.4 \%)$ in the fibrinolysis group and in 135 out of 943 patients $(14.3 \%)$ in the PPCI group $(P=$ 0.21 ). More intracranial hemorrhages occurred in the fibrinolysis group than in the PPCI group $(1.0 \%$ vs. $0.2 \%, P=0.04$; after protocol amendment with a $50 \%$ dose reduction of tenecteplase, $0.5 \%$ vs. $0.3 \%, P=$ 0.45) [24].

In patients with LDL-C > $1.8 \mathrm{mmol} / \mathrm{l}$ (>70 mg/dl) despite a maximum tolerated statin dose who remain at high risk, further therapy to reduce LDLC should be considered (Ila, A)

A meta-analysis of trials comparing more intensive against less intensive lowering of low-density lipoprotein cholesterol (LDL-C) with statins indicated that more intensive statin therapy produced greater reductions in the risks of cardiovascular death, non-fatal MI, ischemic stroke, and coronary revascularization [25]. For every mmol/l reduction in LDL-C, these further reductions in risk were similar to the proportional reductions in the trials of statins vs. control.

In high ischemic-risk patients who have tolerated DAPT without a bleeding complication treatment with DAPT in the form of ticagrelor $60 \mathrm{mg}$ twice a day on top of low-dose aspirin may be considered for up to 3 years (IIb, B)

A total of 21,162 patients after recent MI were randomly assigned to ticagrelor at a dose of $90 \mathrm{mg}$ twice daily, ticagrelor at a dose of $60 \mathrm{mg}$ twice daily or placebo. Patients were also given low-dose aspirin. The two ticagrelor doses each reduced the rate of the composite of cardiovascular death, MI, or stroke as compared with placebo. Rates of thrombolysis in myocardial infarction (TIMI) major bleeding were higher with ticagrelor $(2.60 \%$ with $90 \mathrm{mg}$ and $2.30 \%$ with $60 \mathrm{mg}$ ) than with placebo $(1.06 \%, P<0.001$ for each dose vs. placebo).

Funding Open access funding provided by Medical University of Vienna.

Conflict of interest I.M. Lang declares that she had relationships with drug companies including AOPOrphan Pharmaceuticals, Actelion, Bayer-Schering, Astra-Zeneca, Servier, Cordis, Medtronic, MSD, GSK, Ferrer and Kaneka. In addition to being investigator in trials involving these companies, relationships include consultancy service, research grants, and membership of scientific advisory boards.

Open Access This article is distributed under the terms of the Creative Commons Attribution 4.0 International License (http://creativecommons.org/licenses/by/4.0/), which permits unrestricted use, distribution, and reproduction in any medium, provided you give appropriate credit to the original author(s) and the source, provide a link to the Creative Commons license, and indicate if changes were made.

\section{References}

1. Ibanez B et al. 2017 ESC Guidelines for the management of acute myocardial infarction in patients presenting with STsegment elevation. Eur Heart J. 2017;00:1-66. https://doi. org/10.1093/eurheartj/ehx095

2. Valgimigli M, Gagnor A, Calabro P, Frigoli E, LeonardiS, Zaro T, Rubartelli P, Briguori C, Ando G, Repetto A, Limbruno U, Cortese B, Sganzerla P, Lupi A, Galli M, Colangelo S, Ierna S, Ausiello A, Presbitero P, Sardella G, Varbella F, Esposito G, Santarelli A, Tresoldi S, Nazzaro M, Zingarelli A, de Cesare N, Rigattieri S, Tosi P, Palmieri C, Brugaletta S, Rao SV, Heg D, Rothenbuhler M, Vranckx P, Juni P. Radial versus femoral access in patients with acute coronary syndromes undergoing invasive management: a randomised multicentre trial. Lancet. 2015;385:2465-76.

3. CantorWJ, MehtaSR, YuanF, DžavíkV, WorthleyM, Niemelä K, Valentin V, Fung A, Cheema AN, Widimsky P, Natarajan M, Jedrzejowski B, Jolly SS. Radial versus femoral access for elderly patients with acute coronary syndrome undergoing 
coronary angiography and intervention: insights from the RIVAL trial. Am Heart J.2015;170(5):880-6. https:// doi.org/ 10.1016/j.ahj.2015.08.011

4. Pandie S, Mehta SR, Cantor WJ, Cheema AN, Gao P, Madan M, Niemela K, Rao SV, Schwalm JD, Valentin V, Velianou JL, Jolly SS. Radial versus femoral access for coronary angiography/intervention in women with acute coronary syndromes: insights from the RIVAL trial (radial vs femoral access for coronary intervention). JACC Cardiovasc Interv. 2015;8(4):505-12. https://doi.org/10.1016/j.jcin.2014.11. 017

5. Bonaa KH, Mannsverk J, Wiseth R, Aaberge L, Myreng Y, Nygard O, Nilsen DW, Klow NE, Uchto M, Trovik T, Bendz B, Stavnes S, Bjornerheim R, Larsen AI, Slette M, Steigen T, Jakobsen OJ, Bleie O, Fossum E, Hanssen TA, Dahl-Eriksen O, Njolstad I, Rasmussen K, Wilsgaard T, Nordrehaug JE. Drug-eluting or bare-metal stents for coronary artery disease. NEnglJ Med. 2016;375:1242-52.

6. Raber L, Kelbaek H, Taniwaki M, Ostojic M, Heg D, Baumbach A, von Birgelen C, Roffi M, Tuller D, Engstrom T, Moschovitis A, Pedrazzini G, Wenaweser P, Kornowski R, Weber K, Luscher TF, Matter CM, Meier B, Juni P, Windecker $\mathrm{S}$. Biolimus-eluting stents with biodegradable polymer versus bare-metal stents in acute myocardial infarction: twoyear clinical results of the COMFORTABLE AMI trial. Circ Cardiovasc Interv. 2014;7:355-64.

7. Wald DS, Morris JK, Wald NJ, Chase AJ, Edwards RJ, Hughes LO, Berry C, Oldroyd KG. Randomized trial of preventive angioplasty in myocardial infarction. N Engl J Med. 2013;369:1115-23.

8. Engstrom T, KelbaekH, Helqvist S, Hofsten DE, Klovgaard L, Holmvang L, Jorgensen E, Pedersen F, Saunamaki K, Clemmensen P, De Backer O, Ravkilde J, Tilsted HH, Villadsen AB, Aaroe J, Jensen SE, Raungaard B, Kober L. Complete revascularisation versus treatment of the culpritlesion onlyin patients with ST-segment elevation myocardial infarction and multivessel disease (DANAMI-3-PRIMULTI): an open-label, randomised controlled trial. Lancet. 2015;386:665-71.

9. Smits PC, Abdel-Wahab M, Neumann FJ, Boxma-de Klerk BM,LundeK, Schotborgh CE, PirothZ, HorakD, Wlodarczak A, Ong PJ, Hambrecht R, Angeras O, Richardt G, Omerovic E. Fractional flow reserve-guided multivessel angioplasty in myocardial infarction. NEngl J Med. 2017;376:1234-44.

10. Gershlick AH, Khan JN, Kelly DJ, Greenwood JP, Sasikaran T, Curzen N, Blackman DJ, Dalby M, Fairbrother KL, Banya W, Wang D, Flather M, Hetherington SL, Kelion AD, Talwar S, Gunning M, Hall R, Swanton H, McCann GP. Randomized trial of complete versus lesion-only revascularization in patients undergoing primary percutaneous coronary intervention for STEMI and multivessel disease: the CVLPRIT trial. JAm Coll Cardiol. 2015;65:963-72.

11. Shahzad A, Kemp I, Mars C, Wilson K, Roome C, Cooper R, Andron M, Appleby C, Fisher M, Khand A, Kunadian B, Mills JD, Morris JL, Morrison WL, Munir S, Palmer ND, Perry RA, Ramsdale DR, Velavan P, Stables RH, HEAT-PPCI trial investigators. Unfractionated heparin versus bivalirudin in primary percutaneous coronary intervention (HEATPPCI): an open-label, single centre, randomised controlled trial. Lancet. 2014;384(9957):1849-58. https://doi.org/10. 1016/S0140-6736(14)60924-7

12. Montalescot G, Zeymer U, Silvain J, Boulanger B, Cohen M, Goldstein P, Ecollan P, Combes X, Huber K, Pollack C Jr., Benezet JF, Stibbe O, Filippi E, Teiger E, Cayla G, Elhadad S, AdnetF, ChouihedT, GallulaS, GreffetA, Aout M, ColletJP, Vicaut E. Intravenous enoxaparin or unfractionated heparin in primary percutaneous coronary intervention for ST-ele- vation myocardialinfarction: theinternational randomised open-label ATOLL trial. Lancet. 2011;378:693-703.

13. Collet JP, Huber K, Cohen M, Zeymer U, Goldstein P, Pollack C Jr., Silvain J, Henry P, Varenne O, Carrie D, Coste P, Angioi M, Le Breton H, Cayla G, Elhadad S, Teiger E, Filippi E, Aout M, Vicaut E, Montalescot G. A direct comparison of intravenous enoxaparin with unfractionated heparin in primary percutaneous coronary intervention (from the ATOLL trial). Am J Cardiol. 2013;112:1367-72.

14. Silvain J, Beygui F, Barthelemy O, Pollack C Jr., Cohen M, Zeymer U, Huber K, Goldstein P, Cayla G, Collet JP, Vicaut E, Montalescot G. Efficacy and safety of enoxaparin versus unfractionated heparin during percutaneous coronary intervention: systematic review and meta-analysis. BMJ. 2012;344:e553.

15. Steg PG, Bhatt DL, Hamm CW, Stone GW, Gibson CM, Mahaffey KW, Leonardi S, Liu T, Skerjanec S, Day JR, Iwaoka RS, StuckeyTD, Gogia HS, Gruberg L, French WJ, White HD, Harrington RA. Effect of cangrelor on periprocedural outcomes in percutaneous coronary interventions: a pooled analysis of patient-level data. Lancet. 2013;382:1981-92.

16. Jolly SS, Cairns JA, Yusuf S, Meeks B, Pogue J, Rokoss MJ, Kedev S, Thabane L, Stankovic G, Moreno R, Gershlick A, Chowdhary S, Lavi S, Niemela K, Steg PG, Bernat I, Xu Y, Cantor WJ, Overgaard CB, Naber CK, Cheema AN, Welsh RC, Bertrand OF, Avezum A, Bhindi R, Pancholy S, Rao SV, Natarajan MK, ten Berg JM, Shestakovska O, Gao P, Widimsky P, Dzavik V. Randomized trial of primary PCI with or without routine manual thrombectomy. N Engl J Med. 2015;372:1389-98.

17. Frobert O, Lagerqvist B, Olivecrona GK, Omerovic E, Gudnason T, Maeng M, Aasa M, Angeras O, Calais F, Danielewicz M, Erlinge D, Hellsten L, Jensen U, Johansson AC, Karegren A, Nilsson J, Robertson L, Sandhall L, Sjogren I, Ostlund O, Harnek J, James SK. Thrombus aspiration during STsegment elevation myocardial infarction. N Engl J Med. 2013;369:1587-97.

18. Azzalini L, Sole E, Sans J, Vila M, Duran A, Gil-Alonso D, Santalo M, Garcia-Moll X, Sionis A. Feasibility and safety of an early discharge strategy after low-risk acute myocardial infarction treated with primary percutaneous coronary intervention: the EDAMI pilot trial. Cardiology. 2015;130:120-9.

19. Grines CL, Marsalese DL, Brodie B, Griffin J, Donohue B, Costantini CR, Balestrini C, Stone G, Wharton T, Esente P, Spain M, Moses J, Nobuyoshi M, Ayres M, Jones D, Mason D, Sachs D, Grines LL, O'Neill W. Safety and cost-effectiveness of early discharge after primary angioplasty in low risk patients with acute myocardial infarction. PAMI-II Investigators. Primary Angioplasty in Myocardial Infarction. J Am Coll Cardiol. 1998;31:967-72.

20. Jones DA, Rathod KS, Howard JP, Gallagher S, Antoniou S, De Palma R, Guttmann O, Cliffe S, Colley J, Butler J, Ferguson E, Mohiddin S, Kapur A, Knight CJ, Jain AK, Rothman MT, Mathur A, Timmis AD, Smith EJ, Wragg A. Safety and feasibility of hospital discharge 2 days following primary percutaneous intervention for ST-segment elevation myocardial infarction. Heart. 2012;98:1722-7.

21. MelbergT, Jorgensen M, OrnS, Solli T, EdlandU, Dickstein K. Safetyandhealth statusfollowing earlydischargein patients with acute myocardial infarction treated with primary PCI: a randomized trial. Eur J Prev Cardiol. 2015;22:1427-34.

22. Noman A, Zaman AG, Schechter C, Balasubramaniam K, DasR. Early discharge after primary percutaneous coronary intervention for ST-elevation myocardial infarction. Eur Heart JAcute Cardiovasc Care. 2013;2:262-9. 
23. Hofmann R, James SK, Jernberg T, Lindahl B, Erlinge D, Witt N, Arefalk G, Frick M, Alfredsson J, Nilsson L, Ravn-Fischer A, Omerovic E, Kellerth T, Sparv D, Ekelund U, Linder R, Ekstrom M, Lauermann J, Haaga U, Pernow J, Ostlund O, Herlitz J, Svensson L. Oxygen therapy in suspected acute myocardial infarction. NEngl J Med. 2017;377:1240-9.

24. Armstrong PW, GershlickAH, Goldstein P, Wilcox R, Danays T, Lambert Y, Sulimov V, Rosell Ortiz F, Ostojic M, Welsh RC, Carvalho AC, Nanas J, Arntz HR, Halvorsen S, Huber K, Grajek S, Fresco C, Bluhmki E, Regelin A, Vandenberghe K, Bogaerts K, Van de Werf F. Fibrinolysis or primary PCI in ST-segment elevation myocardial infarction. N Engl J Med. 2013;368:1379-87.
25. Baigent C, Blackwell L, Emberson J, Holland LE, Reith C, Bhala N, Peto R, Barnes EH, Keech A, Simes J, Collins R. Efficacy and safety of more intensive lowering of LDL cholesterol: a meta-analysis of data from 170,000 participants in 26 randomised trials. Lancet. 2010;376:1670-81.

26. Romagnoli E, Biondi-Zoccai G, Sciahbasi A, Politi L, Rigattieri S, Pendenza G, Summaria F, Patrizi R, Borghi A, Di Russo C, Moretti C, Agostoni P, Loschiavo P, Lioy E, Sheiban I, Sangiorgi G. Radial versus femoral randomized investigation in ST-segment elevation acute coronary syndrome: the RIFLE-STEACS (Radial Versus Femoral Randomized Investigation in ST-Elevation Acute Coronary Syndrome) study. J Am Coll Cardiol. 2012;60:2481-9. 